\title{
GIS-BASED MAPPING OF ESTIMATED FLOOD INUNDATION AREA, GEOMETRICAL ASPECT
}

\author{
E. Panidi ${ }^{1, *}$, K. Popova ${ }^{2}$, V. Tsepelev ${ }^{2,3}$ \\ ${ }^{1}$ Saint Petersburg State University, St. Petersburg, Russia - panidi@ya.ru, e.panidi@spbu.ru \\ ${ }^{2}$ ROSHYDROMET North-West Department for Hydrometeorology and Environmental Monitoring, St. Petersburg, Russia \\ ${ }^{3}$ Russian State Hydrometeorological University, St. Petersburg, Russia
}

\begin{abstract}
KEY WORDS: Flood Inundation Area, Digital Elevation Model, GIS-based Mapping, HEC-RAS, HEC-GeoRAS
\end{abstract}
\begin{abstract}
:
A full processing chain for inundation modelling/mapping is implemented in different specialised software like HEC-RAS or Flood Modeller. Alternatively, inundation water level can be estimated separately, and then can be mapped in desktop (universal) Geographic Information System (GIS) software. Last approach can be demanded in a complex already-formed GIS-based mapping processing chains, when inundation area mapping appears only as a step of analysis and mapping technology. This context is usual for cadastral accounting of inundation areas. However, such a processing chain have a lack of computation tools, as currently used desktop GISs (e.g., QGIS, ArcGIS, etc.) capable originally to map only a lake-type inundation areas (certainly, in the case of regular software assembly), while along-the-river inundation should have water surface sloping along the river body.

Addressing to the filling the gap of along-the-river inundation mapping in desktop GIS software, we have developed an approach to mapping of river-type inundation area, and implemented it in a test mode to support cadastral accounting of river flood inundation areas. The approach is based upon geometrical modelling of the water surface only, and is not concerned with consideration of hydrogeological conditions and ground water regime. Being simplified, this technique may be rough tool for the cases when hydrogeological aspect have to be respected, however it is simple for implementation and is useful when estimating topography impact only.
\end{abstract}

\section{INTRODUCTION}

Flood inundation area modelling and mapping compose one of the demanded domains of automated mapping and geospatial analysis. Remote sensing data interpretation ensure operative or retrospective mapping, while hydrological and hydraulic modelling and analysis make it possible to provide predictive mapping. In its turn, predictive mapping of the estimated (or potential) area of flood inundation can help to organize appropriate planning in this area and to mitigate at least some flood damage (Karamouz et al., 2014).

In such a context, inundation area mapping become a significant component of natural hazard management and land cadastre. In Russia, cadastral accounting of river flood inundation areas is established by federal legal act (Russian Government, 2014) to ensure flood damage prevention. Accordingly to this act inundation area have to be modelled and mapped for the flood water levels observed in recurrence intervals of 1, 3, 5, 10, 25, and 50 years. Mapping scales are established as 1:2,000 in settlement areas and 1:10,000 outside of the settlements.

This paper is posing our approach designed to provide GISbased mapping of estimated flood inundation area in a context of its cadastral accounting accordingly to Russian law.

\section{STUDY CONTEXT}

One of most famous software designed for hydrological and hydraulic modelling and applied particularly to the mapping of inundation is HEC-RAS (USACE Hydrologic Engineering Center, 2019). With the help of HEC-GeoRAS (USACE Hydrologic Engineering Center, 2019) or River GIS (Pasiok et al., 2019) add-ons it can be incorporated into common processing chain accordingly with ArcGIS or QGIS desktop GIS software. These add-ons are used to build initial geospatial dataset needed to implement hydraulic model of the river in HEC-RAS at the beginning stage, and to visualize hydraulic computations results (particularly in 2D form, as an inundation area) at the final stage of estimation of the river inundation.

Nevertheless, despite the effectiveness (Ackerman, 2004; Cimpianu, Mihu-Pintilie, 2019) of the HEC-RAS/GISs application to the inundation mapping and despite that the HEC-RAS have become a milestone in its domain (Maidment, 2018); this approach appears not suitable for our purposes.

In our case, we have a list of coordinated water levels estimated for standard recurrence intervals accordingly to the national methodology. Consequently, HEC-RAS processing chain (initial geospatial dataset - hydraulic computations - inundation area mapping) become inapplicable; as we need to accomplish just a final mapping step basing on water levels data instead of hydraulic model.

In addition, standard toolsets of QGIS and ArcGIS (as well as toolsets of other widely used GISs) allow to estimate only the plain lake-type inundation water surface and remain not applicable for the mapping of sloped river-type inundation water surface. Raster approximation tools can be discovered as an instrument for the sloped water surface approximation basing on a number of water levels estimated at some points along the river (as it is presented in our case), but such naive approximation produce significant aberrations if not all the river meanders are marked by points with known water level. When the list of coordinated water levels have a lack of points, approximated water surface can be sloped not along the river,

\footnotetext{
* Corresponding author
} 
but across it. As our experience shows the lack of water level points is presented in almost all cases, while expected water levels are computed at the locations of in-situ hydrological measurements, and in-situ locations are not cover every meander of a river in general case. So, the main issue for us was the need to ensure water surface slope approximation along the river meanders.

The only (known to us) desktop GIS is able to estimate sloped water surface basing on at-the-point water levels that is Panorama GIS (Constructor Bureau Panorama, 2019). However, the analysis of inundation mapping results produced in this software show that its algorithm is not able to ensure along-the-meanders approximation in the case of water level points lack.

\section{STUDY RESULTS}

In accordance to the above-described context, we designed approach to the river inundation area mapping and prototyped mapping technique in the desktop GIS environment using standard tools (tools available in most of desktop GIS software). The approach can be described as a number of restrictions:

1. Initial data is composed by the list of points given by coordinate pairs in some map projection and estimated water surface levels

2. Inundation area is estimated through the subtracting of the raster digital elevation model (DEM) from the water surface (presented in raster form)

3. Linear interpolation of additional water level points is assumed in the case of need along the meandering river center line

4. Water surface approximation have to be produced as spatial interpolation (with zero approximation errors at the initial points)

The computation technique can be split generally into next steps:

1. List of the given initial water level points is added with additional points on river meanders not covered by points

2. Water surface level at newly added points is interpolated along the river center line (in fact, along the polyline composed by the points) using linear interpolation technique accordingly to the ground surface elevations detected at the points on the DEM

3. Modelling area (established accordingly to the used DEM) is segmented into parts that are detected as closest surrounding for each river profile segment (segment between two consequent water level points) - Fig. 1

4. Boundaries of segmented parts of modelling area are discovered as cross sections to the water surface flow directions; height is assigned to every boundary line (equal to the water level point located on it - for the boundaries that cross the river; computed as mean value from the heights of connected boundaries in the cases of boundary lines convergence aside the river) - Fig. 2

5. Water surface raster is interpolated basing on the nodes of boundaries of the modelling area segments; currently we use natural neighbour interpolation - Fig. 3 6. Inundation raster is produced by subtracting DEM from the water surface raster

7. Inundation area contour is delineated on the subtracted inundation raster as zero value contour - Fig. 3

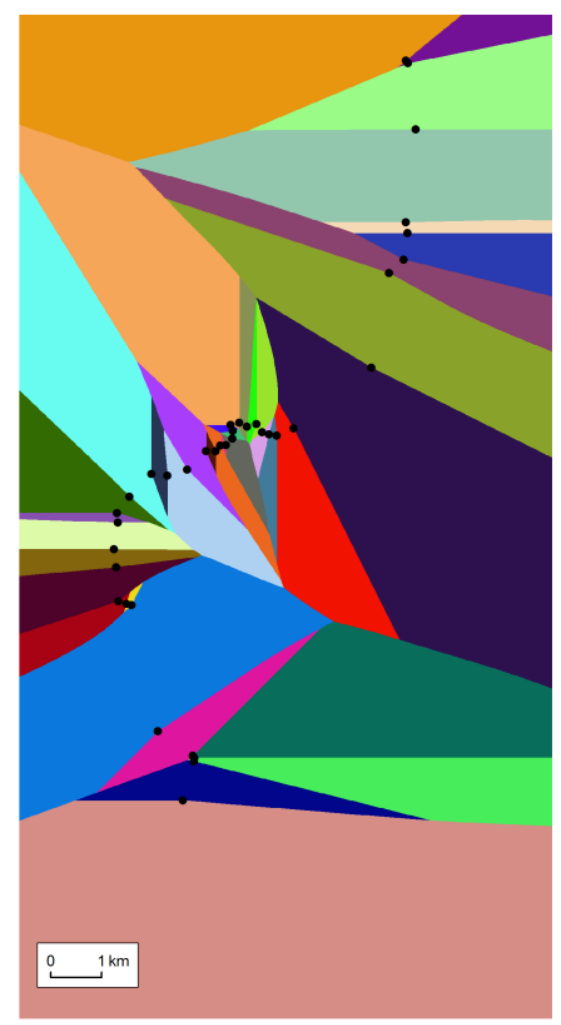

Figure 1. Segmented modelling area; colours are used just to separate different segments; black points are the points of given water levels

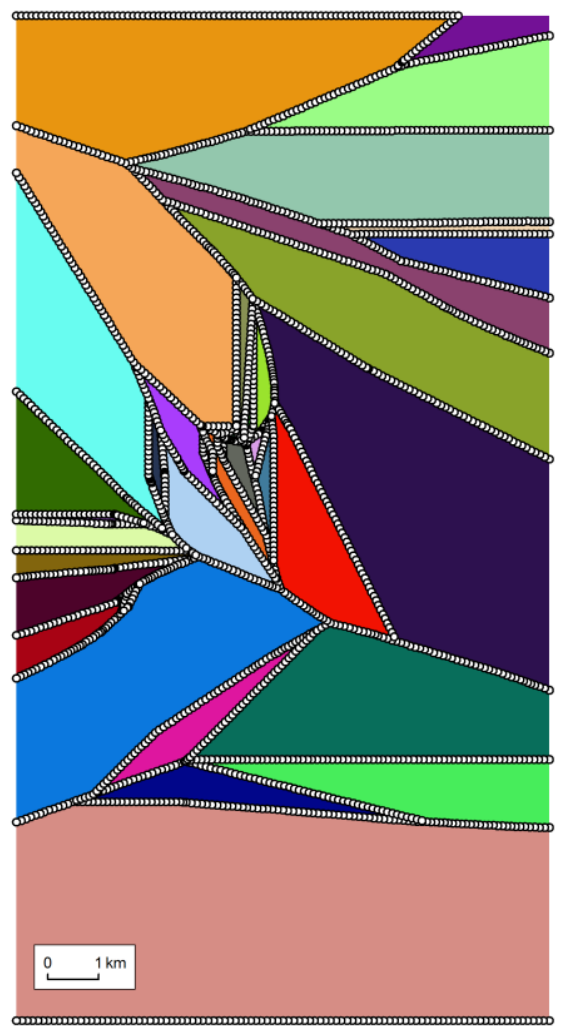

Figure 2. Nodes (white points) of the cross sections derived from the boundaries of modelling area segments (shown by colours equally to the Fig. 1) 


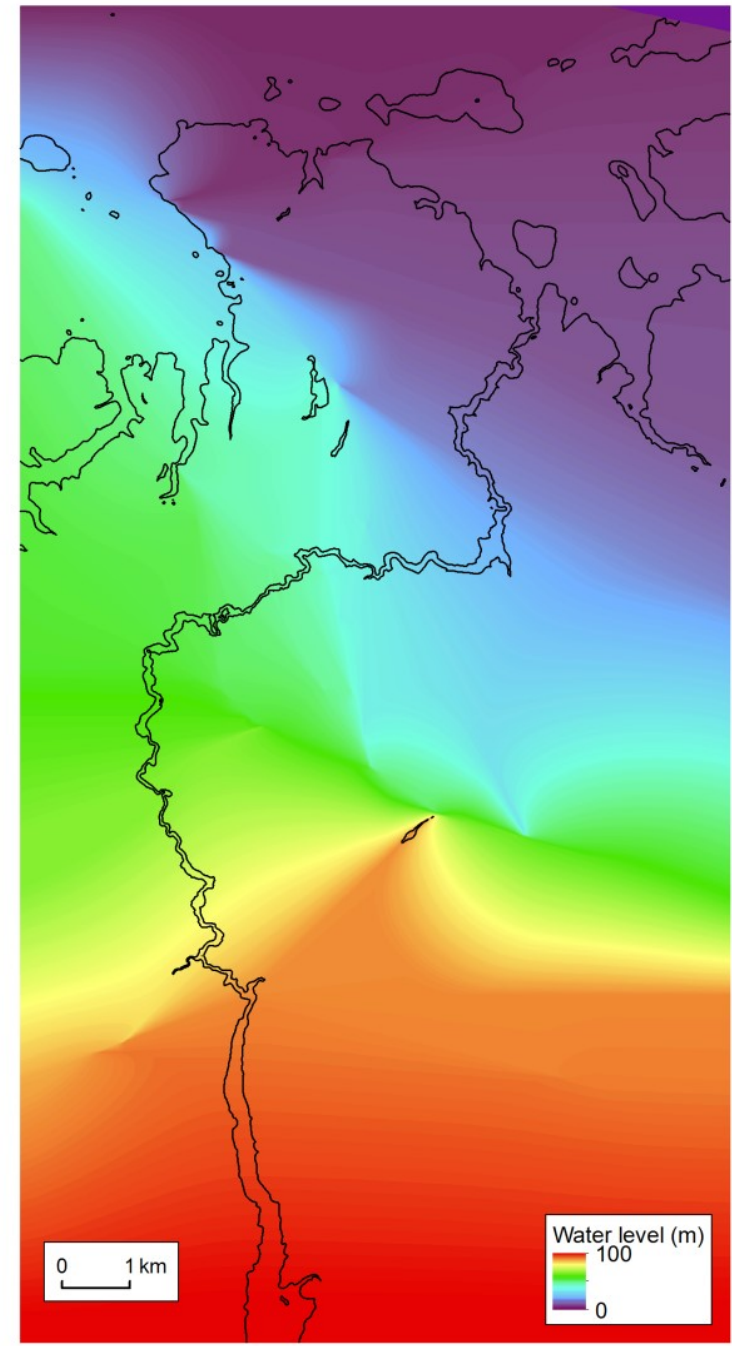

Figure 3. Interpolated water surface with delineated contour of the inundation area

\section{CONCLUSION}

We have designed the approach to the GIS-based mapping of the river flood inundation area, which can be implemented in the cases when inundation water surface is already defined in a number of points and the DEM is available for the area of modelling. In comparison to the HEC-RAS processing chain, our approach is simpler, as it assumes the absence of any special geospatial data model of the river. The approach can be implemented in desktop GISs using common computation tools; we implemented it for the testing purposes in ArcGIS.

However, additional study is demanded to enhance sloped water surface interpolation, as some artefacts can appear aside the river (some examples are seen on Fig. 3). These artefacts are not critical for the case of single river, but can produce errors in the case of modelling of the multi-river system.

\section{REFERENCES}

Ackerman, C.T., 2004: Application of HEC-GEORAS to the Tres Rios, Arizona Feasibility Study. Joint Conference on Water Resource Engineering and Water Resources Planning and Management 2000: Building Partnerships, Vol. 104. doi:10.1061/40517(2000)181
Cimpianu, C.I., Mihu-Pintilie, A., 2019: Open Source Flood Mapping Tools - QGIS, River GIS and HEC-RAS. Proceedings of the 5th International Conference Geobalcanica.

Constructor Bureau Panorama, 2019; Panorama GIS Software. https://gisinfo.ru

Karamouz, M., Zahmatkesh, Z., Goharian, E., Nazif, S., 2014: Coastal Floodplain Mapping and Evaluation Using GIS and HEC-GeoRAS Models. Proceedings of the 2014 World Environmental and Water Resources Congress, 876-886. doi:10.1061/9780784413548.091

Maidment, D., 2018: A New Approach to Flood Mapping. ArcNews, 40(3), 10-11.

Pasiok, R., Dębek, Ł., Parda, R., Zieliński, K., 2019. RiverGIS QGIS plugin. http://rivergis.com/

Russian Government, 2014. The Order of the Russian Federation Government of April 18, 2014 No. 360, About Determination of Borders of the Flooding, Underflooding Zones. (in Russian)

USACE Hydrologic Engineering Center, 2019. HEC-GeoRAS Software. https://www.hec.usace.army.mil/software/hec-georas/

USACE Hydrologic Engineering Center, 2019. HEC-RAS Software. https://www.hec.usace.army.mil/software/hec-ras/

Revised July 2019 